\title{
Video Article \\ Robust Generation of Hepatocyte-like Cells from Human Embryonic Stem Cell Populations
}

Claire N. Medine, Baltasar Lucendo-Villarin, Wenli Zhou, Christopher C. West, David C. Hay

Medical Research Council Centre for Regenerative Medicine, University of Edinburgh

URL: http://www.jove.com/details.php?id=2969

DOI: $10.3791 / 2969$

Keywords: Developmental Biology, Issue 56, Stem Cells, hESC, Development, Endoderm, Liver, Hepatocyte, Endocrine Function, Exocrine Function,

Date Published: $10 / 26 / 2011$

Citation: Medine, C.N., Lucendo-Villarin, B., Zhou, W., West, C.C., Hay, D.C. Robust Generation of Hepatocyte-like Cells from Human Embryonic Stem Cell Populations. J. Vis. Exp. (56), e2969, DOI : 10.3791/2969 (2011).

\section{Abstract}

Despite progress in modelling human drug toxicity, many compounds fail during clinical trials due to unpredicted side effects. The cost of clinical studies are substantial, therefore it is essential that more predictive toxicology screens are developed and deployed early on in drug development (Greenhough et al 2010). Human hepatocytes represent the current gold standard model for evaluating drug toxicity, but are a limited resource that exhibit variable function. Therefore, the use of immortalised cell lines and animal tissue models are routinely employed due to their abundance. While both sources are informative, they are limited by poor function, species variability and/or instability in culture (Dalgetty et al 2009). Pluripotent stem cells (PSCs) are an attractive alternative source of human hepatocyte like cells (HLCs) (Medine et al 2010). PSCs are capable of self renewal and differentiation to all somatic cell types found in the adult and thereby represent a potentially inexhaustible source of differentiated cells. We have developed a procedure that is simple, highly efficient, amenable to automation and yields functional human HLCs (Hay et al 2008 ; Fletcher et al 2008 ; Hannoun et al 2010 ; Payne et al 2011 and Hay et al 2011). We believe our technology will lead to the scalable production of HLCs for drug discovery, disease modeling, the construction of extra-corporeal devices and possibly cell based transplantation therapies.

\section{Video Link}

The video component of this article can be found at http://www.jove.com/details.php?id=2969

\section{Protocol}

\section{Initial preparation of all chemical stocks and coating of culture plasticware}

All steps to be carried out in a tissue culture hood under aseptic conditions.

1. Preparation of human basic Fibroblast Growth Factor (hbFGF)

1. Prepare $10 \%$ BSA solution in PBS and filter through a $0.22 \mu \mathrm{m}$ filter.

2. From the $10 \%$ BSA solution prepare a $0.2 \%$ BSA solution.

3. Add $10 \mathrm{~mL} 0.2 \%$ BSA solution $/ 100 \mu \mathrm{g} \mathrm{hbFGF}$.

4. Pre-wet a $0.22 \mu \mathrm{m}$ filter by filtering $5 \mathrm{~mL} 10 \%$ BSA solution through the filter. Discard the $10 \mathrm{~mL}$ BSA wash.

5. Filter the hbFGF through the pre-washed filter.

6. Aliquot the hbFGF in sterile eppendorfs and store at $-20^{\circ} \mathrm{C}$.

2. Preparation of Human Activin A Stock Solution

1. Add $1 \mathrm{~mL}$ of $0.2 \%$ BSA into a syringe and pre wet the filter.

2. Dilute the Activin A in $0.2 \%$ BSA to a stock concentration of $100 \mu \mathrm{g} / \mathrm{mL}$.

3. Filter the Activin $A$ solution and aliquot in sterile eppendorfs, store at $-20^{\circ} \mathrm{C}$.

3. Preparation of Mouse Wnt3a Stock Solution

1. Add $200 \mu \mathrm{l}$ of PBS to a $2 \mu \mathrm{g}$ vial of Wnt3a to a stock concentration of $10 \mu \mathrm{g} / \mathrm{mL}$.

2. Aliquot in sterile eppendorfs and store at $-20^{\circ} \mathrm{C}$.

4. Preparation of Human HGF Stock Solution (1000X)

1. Dilute the HGF in PBS to a stock concentration of $10 \mu \mathrm{g} / \mathrm{mL}$.

2. Filter the $\mathrm{HGF}$ solution and aliquot in sterile eppendorfs, store at $-20^{\circ} \mathrm{C}$.

5. Preparation of Oncostatin M Stock Solution (1000X)

1. Dilute the OSM in PBS to a stock concentration of $20 \mu \mathrm{g} / \mathrm{mL}$.

2. Filter the OSM solution and aliquot in sterile eppendorfs, store at $-20^{\circ} \mathrm{C}$.

6. Coating of culture plasticware with Matrigel

1. Thaw the $10 \mathrm{~mL}$ stock bottle of Matrigel overnight at $4^{\circ} \mathrm{C}$ on ice and then add $10 \mathrm{~mL}$ of KO-DMEM. Mix well using chilled pipettes and store $1 \mathrm{~mL}$ aliquots at $-20^{\circ} \mathrm{C}$.

2. Thaw an aliquot of Matrigel at $4^{\circ} \mathrm{C}$ for at least 2 hours or overnight to avoid the formation of a gel. 
3. Add $5 \mathrm{~mL}$ of cold $\mathrm{KO}-\mathrm{DMEM}$ to the matrigel, mix well with a pipette.

4. Make up to $15 \mathrm{~mL}$ with cold KO-DMEM and mix using a pipette.

5. Add matrigel to the plate or flask to be coated (Table (i))

\begin{tabular}{ll}
\hline Plate / Flask & Volume / Well or Flask \\
12-well plate & $0.5 \mathrm{~mL}$ per well \\
6-well plate & $1 \mathrm{~mL}$ per well \\
$25 \mathrm{~cm}^{2}$ flask & $2 \mathrm{~mL}$ per flask
\end{tabular}

Table 1. Recommended volumes of matrigel for coating typical plasticware for hESC culture.

6. 6. Incubate the coated plate or flask overnight at $4^{\circ} \mathrm{C}$ or room tempature for 1 hour before use.

7. Plates or flasks which have been coated with matrigel can be stored at $4^{\circ} \mathrm{C}$ for up to 1 week. They should be clearly labelled with the date they were coated. Discard any plates or flasks not used within one week.

1. Before use allow the coated culture container to come up to room temperature inside a tissue culture hood.

2. Immediately prior to use aspirate the matrigel and add the cell suspension to the well or flask.

\section{Routine maintenance of hESC cultures and characterisation}

1. Resuscitation of hESC lines

1. Remove hESCs from liquid nitrogen storage and quickly thaw in a $37^{\circ} \mathrm{C}$ water bath.

2. Transfer the cell suspension carefully to a sterile tube containing several $\mathrm{mL}$ of warm medium.

3. Pellet the cells by centrifugation @ low speed for 5min (1000 RPM).

4. Aspirate off the supernatant and very gently resuspend the cells into warm ES medium and plate out on a MEF feeder layer.

5. Refeed cells daily with fresh ES medium and upon subconfluence, the cells, the cells require passaging.

2. Routine hESC maintenance

ES cells are grown in plates or flasks coated with matrigel. The cells need to be examined and fed daily:

1. Examine under the microscope for contamination, cell morphology and confluence.

2. Aspirate the spent medium.

3. Add an appropriate volume of fresh Mouse Embryonic Fibroblast-Conditioned Medium (MEF-CM) + human bFGF (final concentration 4 $\mathrm{ng} / \mathrm{mL}$ ) or other serum free media ${ }^{6}$.

3. Passaging cells with collagenase

hESC lines (H1, H9 and RCM-1) will reach confluence every 5-7 days following passaging at a 1:3 split ratio. Early passage hESCs in the presence of stroma grow slower and the time on the matrigel can become an important factor. Human ESCs should not be left longer than 14 days on the same matrigel due to matrix degradation and in this instance it may be necessary to passage the cells at a 1:1 or 1:2 split ratio if the cells are subconfluent.

\section{Enzyme Incubation}

1. All steps to be carried out in a tissue culture hood under aseptic conditions.

2. Ensure there is a new matrigel coated dish or flask prepared as per section 1.6

3. Decide on the desired split ratio for the cells. A number of factors are involved in deciding the split ratio:

i. High level of stroma with low numbers of colonies: can be passaged back to a smaller well size or can be passaged 1:1 which will get rid of some stroma and thus increase the colony to stroma ratio, promoting hESC growth.

ii. High level of stroma with large colonies, depending on the number of colonies, can be passaged 1:1 or 1:2 if there are enough large hESC colonies.

iii. Typical growing hESCs with a little stroma or no stroma and/or some differentiation can be passaged 1:2 or 3 .

iv. Aspirate the media from the well or flask.

v. Wash once with $2 \mathrm{mLs}$ PBS $\left(-\mathrm{MgCl}_{2},-\mathrm{CaCl}_{2}\right)$.

vi. Add an appropriate volume of collagenase ( $200 \mathrm{U} / \mathrm{mL}$ diluted in KO-DMEM) and incubate at $37^{\circ} \mathrm{C}$ for $2-5$ min. From 2 minutes onwards examine regularly under the microscope (1 minute intervals). At the point the differentiated cells begin to lift off and the colonies begin to lift at the edge the cells are ready to be passaged.

Scraping and Pooling the hESCs

3.

6. Aspirate the collagenase.

7. Wash once with $2 \mathrm{mLs}$ PBS $\left(-\mathrm{MgCl}_{2},-\mathrm{CaCl}_{2}\right)$.

8. Add an appropriate volume of MEF-CM depending on the split ratio, and using a cell scraper physically remove the cells from the surface of the well or flask, then triturate gently by pipetting up and down 2-3 times using a $10 \mathrm{~mL}$ pipette. It is important that the hESCs are kept in clumps of cells and are not broken up into single cells.

\section{Replating the hESCs}

3.

9. Replate the resulting cell suspension onto the new matrigel coated flasks or wells.

10. Make the volume of MEF-CM up to $4 \mathrm{~mL}$ for a well of a 6 -well plate.

11. When placing the cells in the incubator agitate the tissue culture container to ensure as even as possible a distribution of colonies as the colonies tend to settle in the centre of the tissue culture plate/flask affecting cell replating and differentiation.

4. Routine characterisation of hESC populations by flow cytometry

1. hESC populations are examined via flow cytometry once a month for stem cell markers such as Oct 3/4, Tra 1-60 and SSEA-4. 
2. hESC populations are removed from their substrate as single cell suspensions following a 5 minute treatment with trypsin/EDTA (Invitrogen).

3. Resuspend single cells at $1 \times 10^{6}$ cells $/ \mathrm{mL}$ in PBS supplemented with $0.1 \%$ BSA and $0.1 \%$ sodium azide.

4. Incubate cell preparations at $4^{\circ} \mathrm{C}$ with the appropriate antibodies for 40 minutes.

5. Wash cells twice with PBS supplemented with $0.1 \%$ BSA and $0.1 \%$ sodium azide to remove unbound antibody and resuspend to a final volume of $100 \mu \mathrm{L}$ and analyse by flow cytometry.

6. Data for 30000-40000 "live" events are acquired for each sample using a FACS Caliber cytometer equipped with a 488-nm laser and analyzed using CellQuest software (Becton Dickinson, San Jose, CA). Unstained cells are included as controls. Dead and apoptotic cells along with debris were excluded from analysis using an electronic live gate on forward scatter and side scatter parameters.

\section{Differentiation of hESCs to hepatic endoderm}

1. Preparation of Media for differentiation of hESCs to hepatic endoderm. All media preparation should be carried out in a tissue culture hood under aseptic conditions.

1. Preparation of RPMI:B27 priming medium for endoderm differentiation

1. For RPMI-B27 medium, mix RPMI $1640(500 \mathrm{~mL})$ and B27 $(50 \mathrm{x}, 10 \mathrm{~mL})$

2. Swirl to mix components.

3. Add all components to a filter unit and filter under vacuum, store at $4{ }^{\circ} \mathrm{C}$

2. Preparation of SR-DMSO medium for hepatocyte differentiation

1. For SR-DMSO medium, mix $80 \%$ KO-DMEM, 20\% KO-SR, $0.5 \%$ L-glutamine, $1 \%$ non-essential amino acids, $0.1 \mathrm{mM}$ $\beta$-Mercaptoethanol and $1 \%$ DMSO.

2. Filter the solution under vacum, store at $4{ }^{\circ} \mathrm{C}$ and aliquot and store at $-20{ }^{\circ} \mathrm{C}$ if required.

3. Use $4 \mathrm{~mL}$ per well of a 6 -well plate, and $6 \mathrm{~mL}$ per T25 flask.

3. Preparation of L15 maturation medium for hepatocyte maturation

1. For L-15 medium, mix $500 \mathrm{~mL}$ Leibovitz L-15 medium, tryptose phosphate broth (final concentration $8.3 \%$ ), heat inactivated foetal bovine serum (final concentration 8.3\%), $10 \mu \mathrm{M}$ hydrocortisone 21-hemisuccinate, $1 \mu \mathrm{M}$ Insulin (bovine pancreas), $1 \%$ L-Glutamine, $0.2 \%$ ascorbic acid

2. Filter the solution under vacum, store at $4{ }^{\circ} \mathrm{C}$ and aliquot and store at $-20{ }^{\circ} \mathrm{C}$ if required.

4. Preparation of final RPMI:B27 priming medium

1. Dispense the required volume of priming medium for the experiment ( $1 \mathrm{~mL}$ per well of a 6 -well plate, and $2 \mathrm{~mL}$ per T25 flask).

2. Add Activin A to a final concentration of $100 \mathrm{ng} / \mathrm{mL}$.

3. Add recombinant Wnt3a to a final concentration of $50 \mathrm{ng} / \mathrm{mL}$.

4. Mix well and the media is now ready for use.

5. This final media should be made up fresh each day.

5. Preparation of final $\mathrm{L}-15$ maturation medium

1. Dispense the required volume of $\mathrm{L}-15$ medium for the experiment ( $4 \mathrm{~mL}$ per well of a 6 -well plate, and $6 \mathrm{~mL}$ per T25 flask).

2. Add HGF to a final concentration of $10 \mathrm{ng} / \mathrm{mL}$.

3. Add OSM to a final concentration of $20 \mathrm{ng} / \mathrm{mL}$.

4. Mix well and the media is now ready for use.

5. This final media should be made up fresh each day.

2. Priming hESCs to definitive endoderm

1. Culture hESCs $(\mathrm{H} 1, \mathrm{H} 9$ and RCM-1) and propagate on matrigel coated plates with mouse embryonic fibroblast MEF-CM supplemented with bFGF.

2. Initiate hepatic differentiation when hESCs reach a confluency level of approximately $30 \%-60 \%$ (depending on the hESC line) by replacing the MEF-CM with priming medium (RPMI 1640-B27 supplemented with $100 \mathrm{ng} / \mathrm{mL}$ Activin A and $50 \mathrm{ng} / \mathrm{mL}$ Wnt3a.

3. The cells are cultured in priming medium for 3 days (changing the medium every 24 hours), and final priming medium with Activin A and Wnt3a is made up fresh each day.

4. After 72 hours in priming medium, change the medium to the second differentiation medium (SR-DMSO) for 5 days (changing the medium every 48 hours).

5. At day 8 culture the cells in maturation and maintenance medium (L-15) supplemented with $10 \mathrm{ng} / \mathrm{mL} \mathrm{hHGF}$ and $20 \mathrm{ng} / \mathrm{mL}$ OSM for 9 days (changing medium every 48 hours). Maturation and maintenance medium with hHGF and OSM is made up fresh each day.

6. The cells gradually exhibit morphological changes from a spiky/triangular shape to a characteristic liver morphology displaying a polygonal appearance (Figure 2A).

7. Schematic for hepato-cellular differentiation:

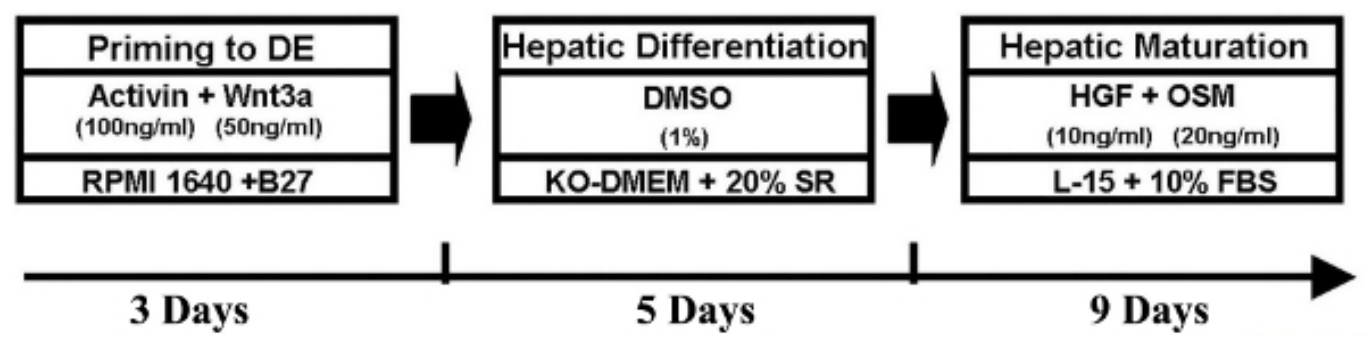

\section{Characterisation of hESC derived hepatic endoderm}

1. Immunostaining

1. Wash hESC derived HLCs with PBS twice, 1 minute each wash. 
2. Fix the HLCs with $4 \%$ PFA for 20 minutes at room temperature, (the cells can be stored in PBS at $4^{\circ} \mathrm{C}$ and stained at a later date). The cells can also be fixed with ice cold methanol for 10 mins at $-20^{\circ} \mathrm{C}$.

3. Wash the cells twice with PBS, 5 minutes each wash.

4. Incubate the cells for 2 minutes at room temperature with $100 \%$ ethanol for nuclear staining (this step is not required if methanol fixation is used).

5. Wash the cells twice with PBS, 5 minutes each wash

6. Block the cells with PBS/T $(0.1 \%$ tween $) / 10 \%$ BSA for 1 hour at room temperature.

7. Remove the blocking buffer and add the respective primary antibody diluted in PBS/T $(0.1 \%$ tween $) / 1 \%$ BSA and incubate for 2 hours at room temperature, or overnight at $4^{\circ} \mathrm{C}$ with agitation.

8. Wash the cells 3 times with PBS/T $(0.1 \%$ tween $) / 1 \%$ BSA at room temperature, 5 minutes each wash.

9. Add the appropriate secondary Alexa Fluor antibody (1:400) diluted in PBS to the cells and incubate at room temperature for 1 hour in the dark with agitation.

10. Wash the cells 3 times with PBS, 5 minutes each wash.

11. Mount each well with MOWIOL 4-88 and DAPI (1:1000). Cover the well with a cover slip, pressing the coverslip gently to ensure that all air bubbles are removed and store at $4^{\circ} \mathrm{C}$ in the dark.

2. RNA isolation and extraction

1. Wash the hESC derived HLCs with PBS and aspirate.

2. Add $1 \mathrm{~mL}$ of TRIZOL reagent and incubate at room temperature for 5 minutes.

3. Scrape the cells and place in a $1.5 \mathrm{~mL}$ eppendorf (store at $-80^{\circ} \mathrm{C}$ for later use if required).

4. Add $0.5 \mathrm{~mL}$ of Chloroform to the eppendorf and mix by inverting; make sure this is done in a fume hood.

5. Centrifuge the solution at 13,000 RPM for 15 minutes at $4{ }^{\circ} \mathrm{C}$

6. Collect the aqueous layer and place into a clean eppendorf, make sure there is no contamination from the interface.

7. Add $1 \mathrm{~mL}$ of isopropanol and mix by inverting, leave at room temperature for 10 minutes to precipitate the RNA.

8. Centrifuge at 13,000 RPM for 10 minutes at $4^{\circ} \mathrm{C}$.

9. Aspirate the supernatant and make sure not to disturb the RNA pellet. Wash with $0.5 \mathrm{~mL}$ of $70 \%$ ethanol and leave at room temperature for 5 minutes.

10. Centrifuge at 8,000 RPM for 5 minutes at $4^{\circ} \mathrm{C}$.

11. Aspirate the ethanol and leave to dry at room temperature for 5-10 minutes.

12. Once all the ethanol has evaporated, resuspend the pellet in $30 \mu$ l of deionised water. Store the RNA at $-80^{\circ} \mathrm{C}$ for later use.

13. Quantify the RNA concentration using a nanodrop.

3. Reverse Transcription PCR

1. Set up a reaction using previously isolated RNA (200 ng), random hexamers, nucleotides (10mM) reverse transcriptase and the respective buffer in a thin walled $0.5 \mathrm{~mL}$ eppendorf.

2. Set up a negative $\mathrm{RT}$, the above reaction without the reverse transcriptase.

3. Place the tubes into a thermo cycler, PCR machine, and set up the following program:

i. $\quad 37^{\circ} \mathrm{C}-5$ minutes (1 cycle)

ii. $42^{\circ} \mathrm{C}-1$ hour ( 1 cycle)

iii. $95^{\circ} \mathrm{C}-5$ minutes ( 1 cycle)

4. Store the $\mathrm{cDNA}$ at $-20^{\circ} \mathrm{C}$ for later use if required.

4. TAQMAN quantitative reverse transcriptase polymerase chain reaction Harvest the cells at different time points throughout the differentiation protocol. Extract the RNA and carry out reverse transcription qPCR using the following primers and Assay on demand, (Applied Biosystems) protocol:

1. Oct $4 \mathrm{Hs} 03005111 \mathrm{~g} 1$

2. Nanog Hs02387400_g1

3. Albumin Hs00910225 $\mathrm{m} 1$

4. Alpha-fetoprotein Hs00173490_m1

For RNA isolation and extraction please refer to section 3.3.2

1. Reverse transcription and TAQMAN qPCR

a. Take $1 \mu \mathrm{g}$ of RNA and reverse transcribe to cDNA using Invitrogen's Superscript III reverse transcription kit, as per manufacturer's instructions.

b. $1 \mu \mathrm{l}$ of the cDNA used in a $25 \mu \mathrm{l}$ TAQMAN reaction consisting of the appropriate primers from Applied Biosystems, $18 \mathrm{~S}$ ribosomal control primers and Invitrogen's 2x platinum qPCR supermix UDG with rox and an appropriate volume of water.

c. Mix well and place $10 \mu \mathrm{l}$ of each sample into two wells of either a 96 or 384 well qPCR plate.

d. Once all samples are loaded, plus the appropriate controls), seal the plate and analyse on the Applied Biosystems 7900HT TAQMAN machine.

e. Results are expressed as relative expression over a control sample.

5. Functional Analysis of hESC Derived Hepatic Endoderm Cytochrome P450 Assays - http://www.promega.com/tbs/tb325/tb325.pdf

1. Incubate day $17 \mathrm{hESC}$ derived $\mathrm{HE}$ with the specific substrate for 5 hours at $37^{\circ} \mathrm{C}(\mathrm{n}=3)$. Use tissue culture media as a negative control and incubate at $37^{\circ} \mathrm{C}$ for 5 hours.

2. Collect the supernatants and carry out the assay as per the manufacturer's instructions.

3. Measure the relative levels of basal activity and normalise to per mg protein as determined by the BCA Assay (http://www.piercenet.com/products/browse.cfm?fldID=02020101).

\section{Notes}

1. All volumes are based on a 6-well plate format. Adjust the volumes accordingly for the required plate or flask

2. All priming, differentiation and maturation medium is filtered under vacuum before use.

3. Priming, differentiation and maturation medium is stored at $4^{\circ} \mathrm{C}$ for no longer than 2 weeks. Assess how much medium is required for the experiment and aliquot the remaining media and store at $-20^{\circ} \mathrm{C}$ for future use.

4. Matrigel is made up as per the manufacturer's instructions; $1 \mathrm{~mL}$ aliquots can be stored at $-20^{\circ} \mathrm{C}$ until use. 
5. Growth factors once made up and aliquoted can be stored at $-20^{\circ} \mathrm{C}$ and when thawed can be stored at $4^{\circ} \mathrm{C}$ for no longer than 2 weeks.

6. The Primary antibody usually used to characterise hESC derived HLCs is albumin (1:250, Sigma-Aldrich, Saint Louis, MO).

\section{Representative Results:}

\section{Characterisation of hESCs maintained prior to hepatic differentiation}

In order to characterise the stem cell status of the H9 hESCs used in the study we studied a number of parameters. The cells exhibited hESC morphology, small, tightly packed cells growing in defined colonies (Figure $1 \mathrm{~A}$ ) and expressed the pluripotent stem cell gene markers, Oct-3/4 and Nanog (Figure 1B). We did not find significant differences in the expression of these genes compared to a H7 hESC line positive control. Additionally, $90.1 \%$ of the hESCs population was positive for the stem cell marker SSEA-4 (Figure 1C).

\section{hESC differentiation to hepatic endoderm}

Human embryonic stem cells can be efficiently differentiated to hepatic endoderm in vitro (Hay et al 2008). At day 9 of differentiation, cells were harvested and differentiation of hESC to HLCs was assessed. As previously reported the hESCs exhibited a series of profound morphological changes, and by day 9, exhibited early hepatocyte morphology developing a polygonal appearance (Figure 2A). Moreover, downregulation of Oct-3/4 over the 9 day time course was observed (Figure 2B). In contrast, liver transcripts AFP and albumin were up-regulated (Figure 2C) from day 7 onwards.

\section{In vitro maturation of Hepatic Endoderm}

Hepatic endoderm was matured in vitro using the established procedure (Hay et al 2008). On the final day of differentiation cultures were immunostained for human liver markers albumin, AFP and E-cadherin. The yield of HLCs using our procedure is typically $90 \%$ (Hay et al 2008 ; Hanoun et al 2010 ; Payne et al 2011). HLCs stained positive for Albumin, Alpha-fetoprotein and E-Cadherin (Figure 3).

A
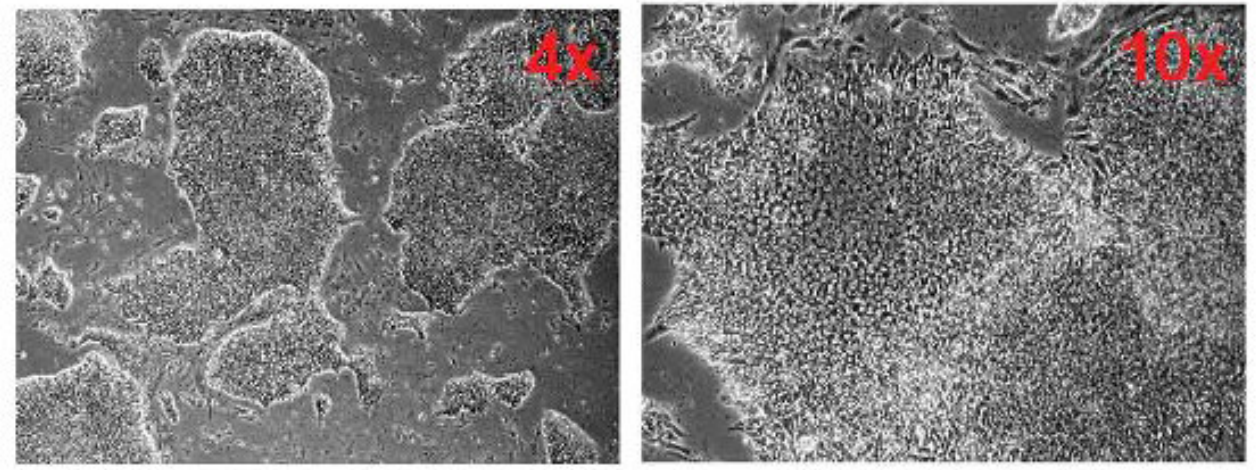

B
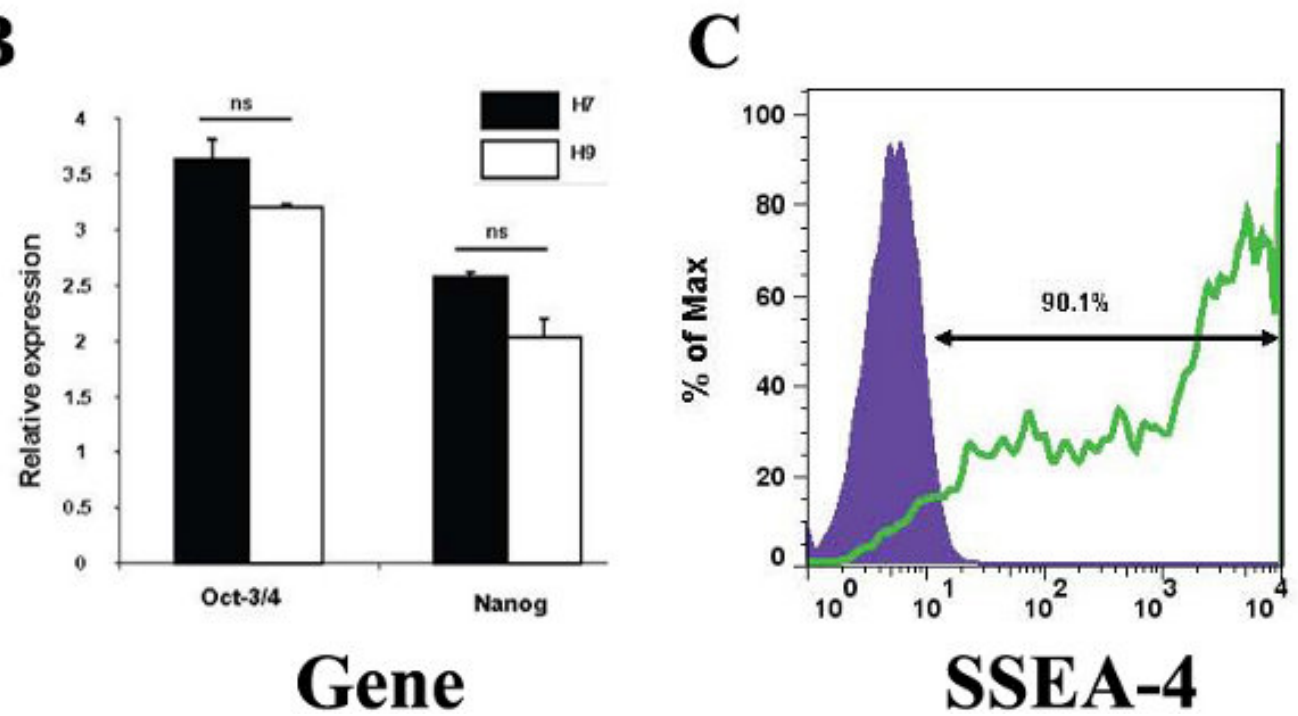

Figure 1. Characterisation of hESCs used in this study. (A) Phase contrast microscopy images representative of hESC morphology observed in culture at $4 x$ and 10x magnification. The images were captured using a Nikon TE3000/U inverted microscope (B) hESCs cultured are Octamer (Oct-3/4) positive and Nanog positive. $\mathrm{H} 7 \mathrm{hESCs}$ were use as a control for pluripotency gene expression levels. Relative expression refers to folds of induction compared with the endogenous gene control, $\beta$-2-microglobulin. (C) FACS plots show hESC surface marker expression levels, including stage specific embryonic antigens SSEA 4. 
A

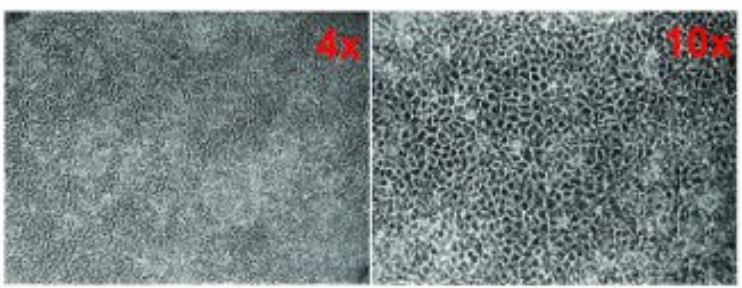

B

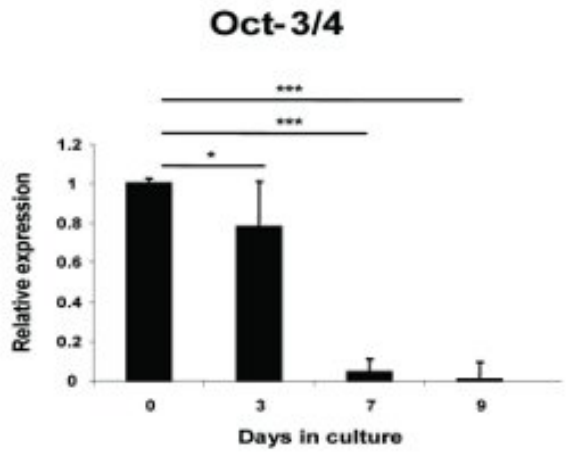

C

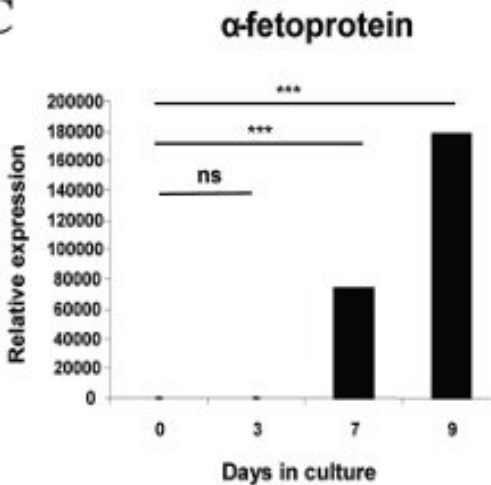

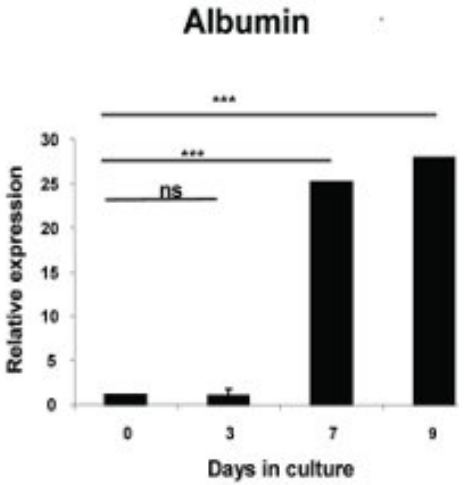

Figure 2. (A) Phase contrast microscopy representative images of hESC-derived hepatic endoderm morphology at day 9 of the differentiation observed in culture, at $x 4$ and $\times 10$ magnification. (B) Characterization of changes in the gene expression. RNA was extracted and the cDNA was analysed by quantitative polymerase chain reaction, showing progressive downregulation of undifferentiated cell gene expression (Oct-3/4) and (C) Upregulation of hepatocyte gene expression (albumin and $\alpha$-fetoprotein). Relative expression refers to folds of induction compared with the endogenous gene control, $\beta$-2-microglobulin at day 0 of differentiation. $\mathrm{P}<0.05$ is denoted ${ }^{*}$ and $\mathrm{P}<0.001$ is denoted ${ }^{* * *}$ measured by students t-test in comparison to hESCs at day 0 . Error bars represent 1 standard deviation. 

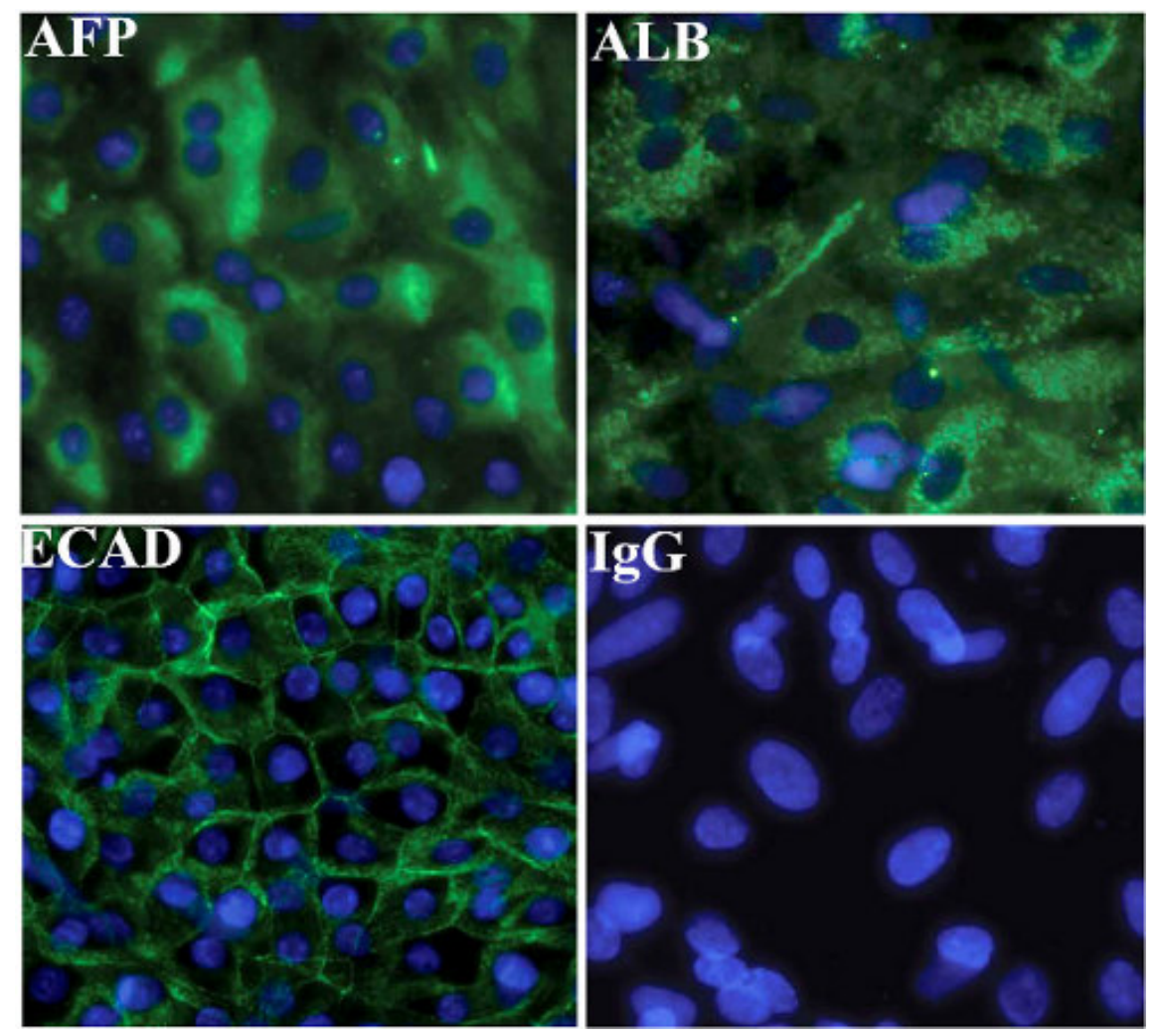

Figure 3. Characterisation of hESC-derived hepatic endoderm

Immunocytochemistry showing expression of hepatocyte markers, albumin, AFP and E-Cadherin in hESC (H9) derived hepatic endoderm. Negative controls were performed with corresponding immunoglobulin $\mathrm{G}(\mathrm{IgG})$ and representatives images are shown.

\section{Cyp3A Function}

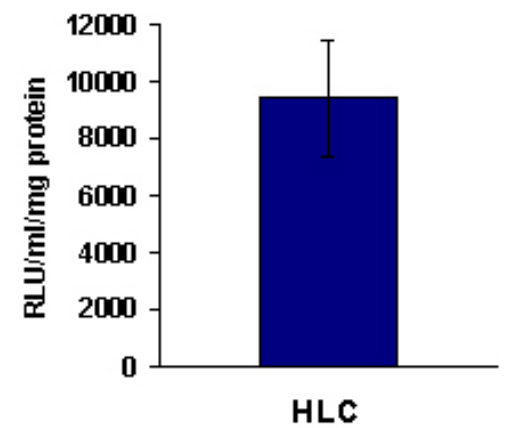

Figure 4. hESC (H9) derived HLCs exhibit metabolic activity. At Day 17, H9 differentiated to HLCs exhibited CYP3A metabolic activity $(n=6)$.

\section{Discussion}

We have developed a simple, homogeneous and highly reproducible in vitro model to generate scalable levels of human HLCs. Our model has been validated by a number of external collaborating laboratories. We routinely characterise stem cell derived HLCs using our in house tool box of developmental markers and liver specific functional assays (most of which are commercially available). The critical stages in our process are: the maintenance of stem cell pluripotency; the ability to direct stem cell differentiation to definitive endoderm; the specification of homogeneous cultures of hepatic endoderm and the ability to derive mature hepatic endoderm exhibiting broad range function in vitro.

One limitation to the large scale deployment of the stem cell derived HLC technology has been the short term differentiated function of mature hepatic endoderm in culture ( 4 days on matrigel). As such we have screened a polymer library for bio-active and novel cellular supports. This has led to the identification of a novel support which maintains hepatic function for at least 15 days. The future directions for this technology are initially industrial application in the drug discovery process (Hay et al 2011). Mid term gains form this technology are likely to be humanised extra-corporeal liver support devices for bridging or treating patients with liver disease. Long term gains from this technology could in cell based transplantation therapy for liver disease, however the current data demonstrates that this strategy requires significant effort before it can be used safely in the clinic (Payne et al 2011).

In conclusion, the significance of our in vitro technology is the ability to generate homogeneous and limitless cultures of high fidelity human HLCs for applied biology. 


\section{Disclosures}

No conflicts of interest declared.

\section{Acknowledgements}

Dr Hay was supported by a RCUK Fellowship, Dr West was supported by the Department of Surgery, Dr Medine was supported by a grant from the BHF Core Fund, Mr. Baltasar Lucendo-Villarin was supported by a MRC PhD Studenship. Dr Zhou was supported by a scholarship from the Chinese Government.

\section{References}

1. Asgari, S., Pournasr, B., Salekdeh, G.H., Ghodsizadeh, A., Ott, M., \& Baharvand, H. Induced pluripotent stem cells: a new era for hepatology. J. Hepatol. 53 (4), 738-51 (2010).

2. Hay, D.C., Pernagallo, S., Diaz-Mochon, J.J., Medine, C.N., Greenhough, S., Hannoun, Z., Schrader, J., Black, J.R., Fletcher, J., Dalgetty, D., Thompson, A.I., Newsome, P.N., Forbes, S.J., Ross, J.A., Bradley, M, \& Iredale, J.P. Unbiased Screening of Polymer Libraries to Define Novel Substrates for Functional Hepatocytes with Inducible Drug Metabolism. Stem Cell Research. 6, 92-101 (2011).

3. Payne, C.M., Samuel, K., Pryde, A., King, J., Brownstein, D., Schrader, J., Medine, C.N., Forbes, S.J., Iredale, J.P., Newsome, P.N., \& Hay, D.C. Persistence of Functional Hepatocyte Like Cells in Immune Compromised Mice. Liver International. 31 (2), 254-62 (2011).

4. Greenhough, S., Medine, C., \& Hay, D.C. Pluripotent Stem Cell Derived Hepatocyte Like Cells and their Potential in Toxicity Screening. Toxicology. 278, 250-255 (2010).

5. Medine, C.N., Greenhough, S., \& Hay, D.C. The Role of Stem Cell Derived Hepatic Endoderm in Human Drug Discovery. Biochemical Society Transactions. 38 (4), 1033-6 (2010).

6. Hannoun, Z., Fletcher, J., Greenhough, S., Medine, C.N., Samuel, K., Sharma, R., Pryde, A., Black, J.R., Ross, J.A., Wilmut, I., Iredale, J.P., \& Hay, D.C. The Comparison between Conditioned Media and Serum Free Media in Human Embryonic Stem Cell Culture and Differentiation. Cellular Reprogramming. 12 (2), 133-140 (2010).

7. Dalgetty, D.M., Medine, C., Iredale, J.P., \& Hay, D.C. Progress and Future Challenges in Stem Cell-Derived Liver Technologies. American Journal of Physiology - Gastrointestinal and Liver Physiology. 297 (2), G241-8 (2009).

8. Hay, D.C., Fletcher, J., Payne, C., Terrace, J.D., Gallagher, R.C.J., Snoeys, J., Black, J., Wojtacha, D., Samuel, K., Hannoun, Z., Pryde, A., Filippi, C., Currie, I.S., Forbes, S.J., Ross, J.A., Newsome, P., \& Iredale, J.P. Highly Efficient Differentiation of hESCs to Functional Hepatic Endoderm Requires ActivinA and Wnt3a Signalling. Proceedings of the National Academy of Sciences U. S. A. 105 (34), 12301-12306 (2008).

9. Fletcher, J., Cui, W., Samuels, K., Black, J.R., Currie, I.S., Terrace, J.D., Payne, C., Filippi, C., Newsome, P., Forbes, S.J., Ross, J.A., Iredale, J.P., \& Hay, D.C. The Inhibitory Role of Stromal Cell Mesenchyme on Human Embryonic Stem Cell Hepatocyte Differentiation is Overcome by Wnt3a Treatment. Cloning and Stem Cells. 10 (3), 331-340 (2008). 